\title{
Wellness and Work: Mixed Messages in Residency Training
}

\author{
Nicholas D. Lawson, MD \\ Georgetown University Law Center, Washington, DC, USA.
}

J Gen Intern Med 35(2):594

DOI: $10.1007 / \mathrm{s} 11606-019-05018-2$

(c) Society of General Internal Medicine 2019

I commend Dr. Meeks and colleagues ${ }^{1}$ for acknowledging the lack of evidence supporting the efficacy of individually based approaches to addressing resident wellness and wellbeing (e.g., mindfulness, resilience training). I also commend the authors for recognizing that current strategies for targeting the "burnout epidemic" in residency remain stubbornly focused on the individual to the exclusion of systematic factors. ${ }^{1}$,

${ }^{2}$ However, I think Dr. Meeks and her colleagues are still too invested in individual, medical approaches to resident wellness and well-being that inadvertently stigmatize vulnerable groups.

Dr. Meeks claims that "high levels of burnout negatively impact individual residents and their patients by contributing to medical errors, lapses in professionalism, and poor patient satisfaction." ${ }^{1}$ The authors also appear to endorse the position of "[a]ccrediting agencies, physician and medical education associations [that] underscore the importance of well-being in the development of the competent, caring, and resilient physician."

Yet current evidence does not support claims that trainees or physicians with burnout, poor well-being, poor health, or disabilities are dangerous or less competent than other clinicians; these comments, which regularly appear in the biomedical literature, ${ }^{2}$ stigmatize clinicians who are overweight, ${ }^{3}$ older, pregnant, or have health conditions or disabilities. ${ }^{2}$

Dr. Meeks also does not problematize the Accreditation Council for Graduate Medical Education's (ACGME) new Common Program Requirements on resident well-being. ${ }^{4}$ These requirements, by stating that well-being is a component of resident competence (VI.C.) and identifying burnout, depression, and substance abuse as indicative of poor well-being ((VI.C.1.e) and VI.C.1.e). (1)), ${ }^{4}$ discriminate against residents with these conditions. ${ }^{2}$

Wellness and well-being initiatives may also provide cover for discrimination in indirect ways. ${ }^{2}$ Decisions to fire residents with mental disorders or disabilities, for example, may be justified on the basis of assumptions regarding burnout or poor well-being

Received April 3, 2019

Accepted April 10, 2019

Published online May 1, 2019 rather than disability. The decision to fire an overweight resident unwilling to participate in a wellness initiative may be framed as inability to "identify strengths, deficiencies, and limits in one's knowledge and expertise" 4 about "appropriate" self-care.

Dr. Meeks also continues to push for "track[ing] physician well-being" 1 and referring trainees "experiencing symptoms of poor mental health or acute crises to qualified individuals for assessment." ${ }^{5}$ Such activities may be legal if directed at medical students. But at the occupational level, resident referrals not adhering to the Americans with Disabilities Act's rules on prohibited medical inquiries are illegal and discriminatory.

Although I have raised these concerns with leaders and general counsel at professional medical organizations for years, the ACGME's requirements have not changed, and these organizations have not been willing to educate members of the academic medical community about the appropriate legal rules that relate to these referrals.

Corresponding Author: Nicholas D. Lawson, MD; Georgetown University Law Center, Washington, DC, USA (e-mail: ndl30@georgetown.edu).

\section{Compliance with Ethical Standards:}

Conflict of Interest: The author declares that he does not have a conflict of interest.

\section{REFERENCES}

1. Meeks LM, Ramsey J, Lyons M, Spencer AL, Lee WW. Wellness and work: mixed messages in residency training. J Gen Intern Med. 2019. https://doi.org/10.1007/s11606-019-04952-5. Published March 28, 2019. Accessed April 3, 2019

2. Lawson ND, Kalet AL. How is "stigma" conceived within the biomedical literature on trainee wellness? A directed content analysis. MedEdPublish. 2019. https://doi.org/10.15694/mep.2019.000032.1. Published February 25, 2019. Accessed April 3, 2019.

3. Yuan CM. Perfect compliance: the 2018 Accreditation Council for Graduate Medical Education well-being survey. Ann Intern Med. 2019;170(4): 257-8.

4. Accreditation Council for Graduate Medical Education. ACGME Common Program Requirements. https://www.acgme.org/Portals/0/PFAssets / ProgramRequirements/CPRs_2017-07-01.pdf Published July 1, 2017. Accessed April 3, 2019.

5. Meeks LM, Jain NR, Herzer K. In Reply to Lawson et al. Acad Med. 2019;94(1):8-9.

Publisher's Note Springer Nature remains neutral with regard to jurisdictional claims in published maps and institutional affiliations. 